\title{
Research on the Formulation of Rural Planning from the Perspective of Integration of Agriculture, Culture and Tourism: A Case Study of Guifengshan Village, Macheng City, Hubei Province
}

\author{
Xuecheng HOU ${ }^{\text {a }}$, Hong XU ${ }^{\text {a, } 1}$, Rui $\mathrm{WANG}^{\text {a }}$ and Minghui $\mathrm{HE}^{\text {a }}$ \\ ${ }^{a}$ School of Urban Construction, Wuhan University of Science and Technology, Wuhan, \\ China
}

\begin{abstract}
With the gradual construction of the land and space planning system and the acceleration of the urban-rural integrated development process, China's rural land planning and preparation have ushered in substantial innovations, and at the same time, they are also facing huge challenges. Among them, the low utilization rate of rural land and cultural desertification are the crux of the lagging rural development. This paper takes Guifengshan Village in Macheng City, Hubei Province as an example. Through the analysis of the current advantages of the village, the analysis of challenges, and the evaluation of the suitability of land use, this paper proposes to promote the mutual benefit of agriculture, culture and tourism, and promote the revitalization of Guifengshan Village, forming a "agricultural industry + characteristic cultural creation + red ecology". "Tourism" jointly develops rural planning strategies. It aims to link rural agriculture, tourism and cultural industries closely on the basis of people-oriented and ecological protection, with income generation as the goal of rural revitalization, to achieve the establishment and extension of the industrial chain, and to promote rural revitalization.
\end{abstract}

Keywords. Rural revitalization, industrial convergence

\section{Introduction}

In 2019, the Central Committee of the Communist Party of China and the State Council put forward the "Several Opinions on Establishing a Territorial and Spatial Planning System and Supervising Implementation", and the compilation of territorial and spatial planning was carried out by classification. Among them, township-level land and space planning, as the smallest unit of land compilation, is also an important research direction to help rural revitalization. In recent years, with the rapid development of rural tourism in China, the lack of rural planning leads to the over-exploitation of rural resources, which not only damages the tourism environment, but also damages the

\footnotetext{
${ }^{1}$ Hong Xu, School of Urban Construction, Wuhan University of Science and Technology, Wuhan, China; E-mail: xuhong@wust.edu.cn.
} 
cultural resources. Rural development towards hollowing out and cultural desertification.

From the perspective of the integration of agriculture, culture and tourism, this article takes Guifengshan Village in Macheng City, Hubei Province as an example, explores a rural planning strategy based on people-oriented, ecological protection and scientific evaluation, and establishes a development direction and industrial development for Guifengshan Village based on local conditions. Features, promote the construction of a modern economic system, and provide thinking and reference for the planning and preparation of more similar types of villages.

\section{Analysis of the Current Situation of Guifeng Mountain Village}

\subsection{Existing Advantages: Government Support and Long History}

Gufeng Mountain Village, located in the east of Macheng city, is the core part of national 4A scenic spot Gufeng Mountain (figure 1). It has a forest coverage rate of more than $70 \%$, rich wildlife resources, famous tea brands, and ancient rhododendron native communities with a growth cycle of tens of thousands of years. In Macheng Tourism Development Plan of Hubei Province (2015-2030), the function of Gufeng Mountain tourism area is oriented to ecological tourism, leisure summer, health and health, and sports tourism. The theme image is god turtle longevity, health and no border.

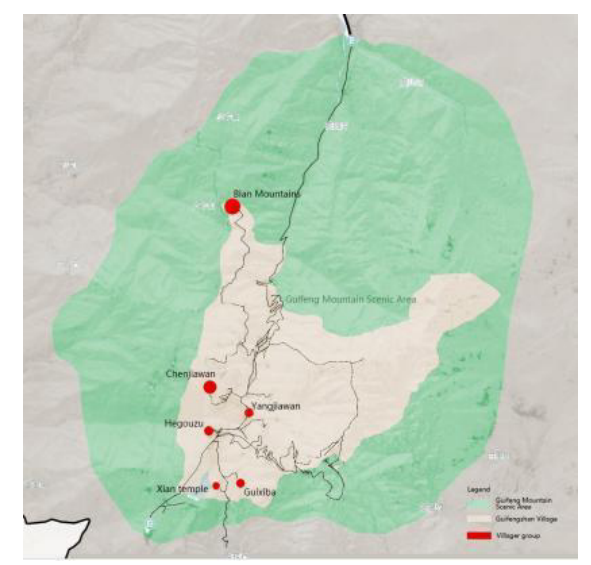

Figure 1. Village-level location map (Source: Self-painted by the author).

\subsection{Current Challenges: A Single Industrial Structure and Poor Infrastructure}

In the process of tourism economic development in Guifeng Mountain village, most of the villagers began to operate the farmhouse, which led to the stagnation of the local characteristic tea industry. The location distribution of the five groups in the village is uneven, and the development level is very different. Remote villages lack of transportation, meat market, schools, health centers and other infrastructure, no tap water supply, and household waste treatment is not timely, the villagers' normal life needs can not be met. 


\section{Planning Strategy and Scientific Evaluation}

Adhering to the concept of "agriculture is the root, culture is the soul, and tourism is the road", we optimize the rural space layout according to local conditions, and take the road of integrating agriculture, culture and tourism with the characteristics of red tourism culture.

\subsection{Ecological Function Suitability Evaluation}

According to the comprehensive index of land ecological function suitability of Guifengshan Village, the correlation between land type and ecological function is repeatedly tested, and the grade threshold value obtained from the experiment is taken, and Guifengshan Village is divided into the most suitable area, suitable area, and barely suitable area. There are 4 grade areas, namely, unsuitable area and unsuitable area [1] The evaluation diagram is shown in figure 2 , and the evaluation results are shown in table 1 .

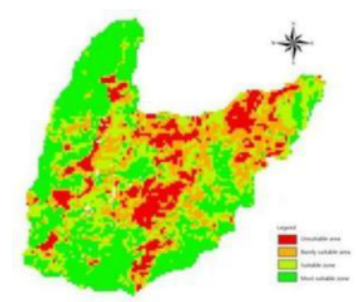

Figure 2. Appraisal map of ecological function suitability of Guifengshan Village (Source: Self-painted by the author).

Table 1. Evaluation results of ecological function suitability of Guifengshan Village.

\begin{tabular}{lll}
\hline Ecological function adaptability level & Composite Index & Number of grids \\
\hline Most suitable zone & 7.5 & 2987 \\
Suitable zone & $6.5-7.5$ & 1916 \\
Barely suitable area & $5.5-6.5$ & 1746 \\
Unsuitable area & $<5.5$ & 1037 \\
Total & & 7686 \\
\hline
\end{tabular}

The ecological most suitable area of Gufeng Mountain village accounts for $38.86 \%$ of the total area, which is evenly distributed in the gufeng Mountain village and provides rich biological resources. The areas with barely suitable ecological function and the areas with unsuitable ecological function account for $36.20 \%$ of the total area. The suitability of construction land is high, which can vigorously develop tourism, but will destroy the suitability of ecological function.

\subsection{Evaluation of Suitability of Construction Land}

In the evaluation of the suitability of construction land in Gufeng Mountain Village, the most suitable and suitable areas are mainly concentrated near the main road of Gufeng mountain village, which belong to the core area, and can be appropriately added to the 
supermarket, medical places and other projects, and play a certain role in drainage [2]. The evaluation diagram is shown in figure 3 , and the evaluation results are shown in table 2 .

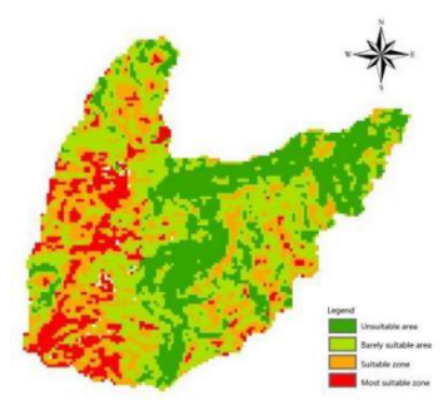

Figure 3. Appraisal map of suitability of construction land in Guifengshan Village (Source: Self-painted by the author).

Table 2. Evaluation results of suitability of construction land in Guifengshan Village.

\begin{tabular}{lll}
\hline $\begin{array}{l}\text { Standard grade of suitability for } \\
\text { construction land }\end{array}$ & Composite Index & Number of grids \\
\hline Most suitable zone & $\geq 7$ & 988 \\
Suitable zone & $6 \sim 7$ & 2050 \\
Barely suitable area & $5 \sim 6$ & 3259 \\
Unsuitable area & $<5$ & 2262 \\
Total & & 8559 \\
\hline
\end{tabular}

\subsection{Suitability Evaluation of Tourism Resources}

It can be seen from the suitability result chart of ecotourism (figure 4) that the natural bay in the southwest of Gufeng Mountain Village and the areas where scenic spots are concentrated have a high tourism ecological bearing capacity. Under the premise of ecological protection, ecotourism projects can be developed and related facilities with weak interference to the ecological environment can be built [3]. The western suitable area is suitable for commercial development. The east of central China and the unsuitable area in northeast China had the highest ecological sensitivity and the lowest ecological bearing capacity.The evaluation results are shown in table 3 .

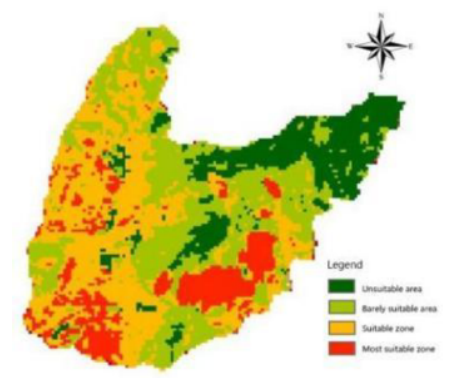

Figure 4. Guifeng Mountain Village's Suitability Evaluation Map for Tourism Resources (Source: Selfpainted by the author). 
Table 3. Evaluation Results of Suitability of Tourism Resources in Guifeng Mountain Village.

\begin{tabular}{lll}
\hline Suitability level of tourism resources & Composite Index & Number of grids \\
\hline Most suitable zone & $\geq 7.5$ & 1670 \\
Suitable zone & $6.3-7.5$ & 2927 \\
Barely suitable area & $5-6.3$ & 2541 \\
Unsuitable area & $<5$ & 1513 \\
Total & & 8651 \\
\hline
\end{tabular}

\section{Strategic Position}

\subsection{Land Spatial Pattern}

According to the spatial layout of Guifengshan Village, the overall spatial layout of "1135" is formed, that is, a coordinated development pattern of village agriculture, culture, tourism, and tertiary industry of "one core town, one core leading, three industries synergy, and five districts linkage". The plan is to build the three cores of agriculture, cultural and tourism in Guifeng Mountain Village, forming an agglomeration area with the coordinated development of agriculture, cultural and creative industries, and tourism. Guifeng Mountain Village will be the leader of the coordinated development of tertiary industries in Guifeng Mountain Scenic Area and lead Macheng Turtle The development of Fengshan Scenic Area. One heart refers to Yangjiawan and one core refers to Yangjiale. The five areas are Yangjiawan, Bian Mountains, Chenjiawan, Hegouzu, and Xian Temple, Guixiaba are linked (figure 5).

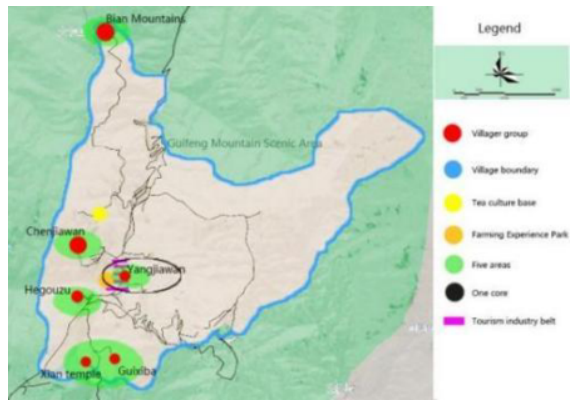

Figure 5. Overall spatial planning layout of Guifengshan Village (Source: Self-painted by the author).

\subsection{Special Planning}

Improve basic service Spaces such as medical service centers, rest centers and conference office centers (figure 6), attach importance to the construction of infrastructure, and do a good job in supporting the development of local tourism; Create tourist service center and rest area center as service space for tourists to provide one-stop service. At the same time, an exhibition center will be set up to display the development of three industries and cultural deposits of Guifeng Mountain Village in various forms, and promote the integration of industries and the coordinated development of the village. Layout and construction of guifeng mountain village 
industrial chain. Relying on the existing industrial foundation, the characteristic industries of Gufeng mountain village should be developed in different regions, and different modes of operation should be developed to realize the ecological, block and comprehensive development of agricultural cultural tourism industry and improve the comprehensive productivity level of Gufeng mountain village [4].

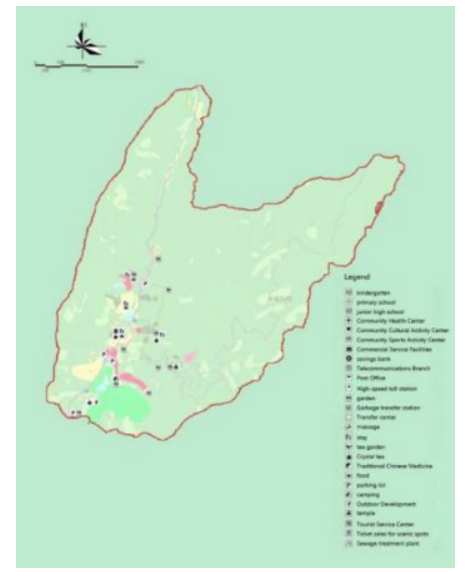

Figure 6. Infrastructure planning drawing (Source: Self-painted by the author).

\section{Planning Characteristics}

\subsection{Expansion of Advantageous Agricultural Industry to Realize "Agriculture +"}

Break the limitation of traditional agriculture, put forward the concept of interactivity into leisure agriculture [5]. For example, a tea culture experience museum can be set up in the tea garden slope field of Gufeng Mountain Village to display tea history and tea making.

\subsection{Integrate Local Culture to Build Brand and Develop Cultural and Creative Industry}

Seek the combination and innovation of local red culture and the characteristics of the new era. The construction of red tourism service center, the use of red rhododendron culture rhododendron sea is a landmark tourist point of Gufeng mountain village, the development of rhododendron ornamental value and industrial value, to create souvenirs, processed food, cultural products, etc [6].

\subsection{The Integration of Agricultural, Cultural and Tourism Industries and the Construction of High-quality Goods}

On the basis of consolidating traditional agriculture, we will further cultivate a new type of agriculture in the countryside, and integrate into the construction of cultural boutiques under the premise of protecting the ecology, and form distinctive local characteristics [7]. With agriculture as the economic foundation, cultural creativity as 
the theme, and tourism as the framework, we will promote the coordinated development of the agricultural, cultural and tourism industry, and achieve a win-win situation where the industrial economy of Guifeng Mountain Village is booming and the villagers generate income [8].

\section{Conclusion}

Taking Gufeng Mountain Village in Macheng City, Hubei Province as an example, this paper puts forward the land planning concept of "promoting rural development by integrating agriculture, culture and tourism" based on the basic conditions of Gufeng Mountain Village through field investigation and scientific evaluation. By GIS software qualitative quantitative analysis about the present situation of land use, the village land suitability evaluation of land, and gives Suggestions for guifeng mountain village land use planning, in order to realize the resource sharing, promoting farmers brigade complementary and mutually beneficial, drive the guifeng mountain, forming "wen gen + red + characteristics of agricultural industry ecological tourism" mutual fusion beautiful country of the development of the new situation.

\section{Acknowledgments}

This research was funded by the Hubei Province University Student Innovation and Entrepreneurship Training Project (S202010488028), Key research projects of philosophy and social sciences of Hubei Provincial Department of Education (Grants\#20D025).

\section{References}

[1] Peng Y, Rural land suitability assessment and its application in planning based on GIS: A case study of Yannan Village. Nanjing Agricultural University. 2013 May; 5-33.

[2] Wang SJ, Chen J, Research on building database of land use planning data at township level based on ArcGIS. Construction of Old Area. 2013 Apr; 36(8): 21-23.

[3] Zhang XY, Research on Planning of wetland ecotourism based on spatial analysis function of GIS Northeast Agricultural University. 2016 Jun; 27-42.

[4] Wang YH, A study on the planning strategy of beautiful countryside under the guidance of type experience: A case study of She Village, Jiangning District, Nanjing. Construction of Small Towns. $2020 \mathrm{Jan} ; 38(1): 35-42$.

[5] $\mathrm{Xu} \mathrm{LF}$, Wang W, Study on countermeasures of integrating agriculture, culture and tourism to help Zhejiang rural revitalization. Henan Agriculture. 2019 Jan; 32(1): 4-5.

[6] Wang HB, Sun WF, Research on the integrated development and quality Promotion strategy of linyi red tourism products from the perspective of rural revitalization. Tourism Overview (second half). 2019 Jun; 31(12): 92+94.

[7] Ai N, Interpretation of the central document No.1 by spiritual experts. Agricultural knowledge: Getting Rich and Agricultural materials. 2015 Mar; 72(7): 1.

[8] Cao LL, Research on countermeasures of rural revitalization in Zhejiang by integrating agriculture, culture and tourism. Modern Rural Science and Technology. 2019 Aug; 48(8): 99-101. 